This is an author produced version of a paper published in Journal of veterinary behavior-clinical applications and research. This paper has been peer-reviewed and is proof-corrected, but does not include the journal pagination.

Citation for the published paper:

Backström, Tobias; Heynen, Martina; Brännäs, Eva; Nilsson, Jan and Magnhagen, Carin. (2015) The effect of anesthetics on carotenoid pigmentation and behavior in Arctic char (Salvelinus alpinus). Journal of veterinary behavior-clinical applications and research. Volume: 10, Number: 2, pp 179-184.

http://dx.doi.org/10.1016/j.jveb.2014.11.007.

Access to the published version may require journal subscription. Published with permission from: Elsevier.

Epsilon Open Archive http://epsilon.slu.se 


\title{
The effect of anesthetics on carotenoid pigmentation and behavior in Arctic charr (Salvelinus alpinus)
}

\author{
T. Backström ${ }^{\mathrm{a}}$, M. Heynen ${ }^{\mathrm{a}}$, E. Brännäs ${ }^{\mathrm{a}}, \mathrm{J}_{\text {. Nilsson }}^{\mathrm{a}}$, and C. Magnhagen ${ }^{\mathrm{a}}$ \\ ${ }^{a}$ Department of Wildlife, Fish, and Environmental Studies, Swedish University of \\ Agricultural Sciences, Skogmarksgränd, SE-901 83 Umeå, Sweden \\ * Present address: Department of Ecology and Environmental Science, Umeå University, \\ SE-901 87 Umeå, Sweden
}

Corresponding author: Tobias Backström, Email: tobias.backstrom@slu.se

\begin{abstract}
Status of individual animals is often shown in pigmentation. For instance, stress responsiveness is associated with melanin-based pigmentation in vertebrates in general. This pattern is evident in Atlantic salmon (Salmo salar) and rainbow trout (Onchorhynchus mykiss) with melanin-based spots indicating stress coping style. Arctic charr (Salvelinus alpinus) differ from other salmonids in pigmentation but have an association between carotenoid-based pigmentation and stress coping style. These pigmentation differences could be used as a fast and simple tool for improving breeding programs. However, the procedure for photographing individuals is stressful. Therefore we wanted to investigate if three common inhalation anesthetics could be used to reduce the stress involved in the procedure compared to a no-anesthetics group. Behavior was also monitored during the anaesthetization. All three anesthetics (AquaCalm, Benzocaine, and MS-222) differed in pigmentation compared to the no-anesthetics group, by having a higher number of spots. In the anesthetic treatments as well as the no-anesthetics group the fish had elevated plasma cortisol levels. In fact the no-anesthetics group had higher cortisol than treated fish. This was probably procedural differences such as time affecting the stress response. Further, in a longterm experiment all fish survived and had similar condition factors one week after photographing as before. Therefore the method for photographing Arctic charr is deemed safe and could be used for as a tool for estimating stress coping style, but careful planning is needed for experiments using it.
\end{abstract}

Keywords: anesthetics; animal welfare; Arctic charr; carotenoid pigmentation; stress 
In animals, stress responsiveness is often connected with personality, and individuals have been divided into proactive (bold), with a low hypothalamic-pituitary-adrenal (HPA) axis reactivity, high aggression levels and social dominance, and reactive (shy) individuals with a high HPA axis reactivity, low degree of aggression and low social ranking (Koolhaas, 2001; Koolhaas et al., 2007; Koolhaas et al., 1999). The occurrence of an inherited variation in stress coping styles, within species and populations, is well recognized among many animal taxa (Gosling, 2001; Hessing et al., 1993; Koolhaas et al., 1999; Sloan Wilson et al., 1994) including teleost fish (Conrad et al., 2011; Schjolden and Winberg, 2007; Øverli et al., 2005).

There are several important applications of being able to identify animals' personality, for example, by reducing the within-treatment variation in experimental designs and consequently the number of required experimental animals (Erhard et al., 1997). Also, personality is an inherited trait and the identification of a desirable personality may be used in selection programs, provided there are no undesirable changes in another trait, to improve domestication and welfare of farmed animals. This is especially relevant in animals which are new in the farming industry, such as fish in intensive fish farming (Duarte et al., 2007). In aquaculture, welfare is an important issue and may be connected to the existence of coping styles (Huntingford et al., 2006). For example, domestication and selection for fast-growing fish may also lead to the selection for a personality type with a more risk-taking, aggressive behavior (Huntingford and Adams, 2005) and the welfare may be compromised for fish of a shyer disposition. Personality in animals is commonly evaluated with stress physiology tests in combination with behavioral screening such as dominance tests, resident-intruder tests, and confinement tests (Koolhaas et al., 1999). These tests compose different challenges in terrestrial compared to aquatic animals. To evaluate personality of individual fish in a brood stock which may comprise of several hundred individuals is an almost undoable task by using any of the standard behavioral tests used for fish. If there was a visual cue that were related to coping style or stress response it becomes realistic that behavioral types can be identified and used as a selection criteria in breeding programs for fish.

Pigmentation in animals often reflects the status of an individual in different respects, such as health, immune system, and body condition [reviewed by Ducrest et al. (2008) and Svensson and Wong (2011)]. A variation in pigmentation among individuals can be used for signaling this status, often used in courtship and aggressive displays (Berglund et al., 1996). It may sometimes be possible also for scientists to use pigmentation of their study animal, to assign conspecifics into different behavioral personalities. For example, in the salmonids Atlantic salmon (Salmo salar) and rainbow trout (Oncorhynchus mykiss), individuals with different stress coping style could be visually separated by the number of melanin-based pigment spots, with proactive individuals having more spots than reactive individuals (Kittilsen et al., 2009). The same pattern, with darker animals being less sensitive to stress, is apparent in vertebrates in general (Ducrest et al. 2008).

However, Arctic charr (Salvelinus alpinus) differs from other salmonids in several aspects including pigmentation (Klemetsen et al., 2003; Shahidi et al., 1994). Recently it has been reported that stress response in Arctic charr is correlated to the light red carotenoid-based pigmentation with proactive individuals having fewer spots than reactive individuals (Backström et al., 2014). A strong genetic effect on the number of carotenoid-based spots was also found after photographing more than 2000 individuals of 60 families in an Arctic charr brood stock (Nilsson et al., manuscript). These findings suggest that the carotenoidbased pigmentation can be evaluated as a visual cue to group Arctic charr into different stress coping styles. However, the individual pigmentation can be affected by acute stress such as in 
a test of dominance between two size-matched individuals where the number of spots was reduced in the dominant fish (Backström et al., 2015).

The evaluation of using carotenoid-based pigmentation for determining individual Arctic charr's personality in a breeding program would benefit from a standardized procedure for taking photographs. Since it is stressful for the fish to be lifted in the air for photographing, using an anesthetic could alleviate the following stress response. However, it is unknown if the carotenoid-based pigmentation is affected by anesthesia and if different anesthetics have different effects. Therefore this study aimed to investigate if three commonly used compounds of inhalation anesthetics affected the carotenoid-based pigmentation in Arctic charr compared to a no-anesthetics group and a group not subjected to the photographing procedure, and if they affected condition after the procedure of photographing. Furthermore, behavior during the anesthetization process was also monitored for differences in anesthetic effects on behavioral and physiological stress responses.

\section{Material and Methods}

\section{Animals and location}

Juvenile Arctic charr from the $7^{\text {th }}$ generation of the Swedish Arctic charr breeding program [Arctic superior, for details on the program see Nilsson et al. (2010)] were bred at the Aquaculture Centre North in Kälarne ( $\left.62^{\circ} 58^{\prime} \mathrm{N} ; 16^{\circ} 5^{\prime} \mathrm{E}\right)$, Sweden. Several months before the experiment the Arctic charr were transported to the Umeå Marine Research Station (UMF) $\left(63^{\circ} 35^{\prime} \mathrm{N} ; 1^{\circ} 50^{\prime} \mathrm{E}\right)$, where the experiment was performed in May-June 2012 on one year old fish. The fish were kept in tanks $(1000 \mathrm{~L})$ supplied with running brackish water (3-4\%) from the Bothnian Bay with a temperature ranging between $5-10{ }^{\circ} \mathrm{C}$ and a photoperiod set to $12 \mathrm{~h} \mathrm{light} / 12 \mathrm{~h}$ dark. The fish were fed commercial pellets (Biomar, $4 \mathrm{~mm}$, www.biomar.com) at 1.0-1.5\% of body mass per day depending on temperature.

\section{Anesthetics}

The anesthetics used were MS-222 (Ethyl 3-aminobenzoate), Benzocaine (Ethyl 4aminobenzoate) and AquaCalm (Metomidate). The first two are chemically very similar and the only ones which are allowed to be used in fish for human consumption within the EU (EEC Council regulation 2377/90). MS-222 is readily dissolved in water, whereas Benzocaine is almost insoluble in water and must first be dissolved in ethanol. MS-222 may reduce $\mathrm{pH}$ in the water and thereby be an irritant for some fishes and therefore cause a stress reaction (Ross and Ross, 2008), whereas Benzocaine is neutral in water. Even when fish are deeply anaesthetized with MS-222, handling has been shown to activate the hypothalamic pituitary interrenal (HPI) axis, as evidenced by increases in circulating plasma cortisol concentrations (Pickering et al., 1982; Thomas and Robertson, 1991). Metomidate, the active compound in AquaCalm, has a more hypnotic effect with potential cortisol suppressing properties by blockage of release from the inter-renal cells (Olsen et al., 1995; Small, 2003). This drug causes drastic reduction in blood pressure in rainbow trout (Fredricks et al., 1993). Of special relevance are earlier findings that there was no cortisol response to handling stress in metomidate sedated Atlantic salmon (Olsen et al., 1995). However, metomidate is not allowed to be used in fish for human consumption within the EU. 


\section{Experiment 1: Immediate effect of anesthetics}

For the first experiment fish [body mass $\left(M_{\mathrm{B}}\right)$ of $133.9 \pm 28.8 \mathrm{~g}$ (mean $\left.\pm \mathrm{SD}, \mathrm{N}=94\right)$ and a fork length $\left(L_{\mathrm{F}}\right)$ of $23.4 \pm 1.5 \mathrm{~cm}$ (mean $\left.\pm \mathrm{SD}, \mathrm{N}=100\right)$ ] were randomly selected from the holding stock and assigned to five different treatment groups. Three treatments were anesthetic solutions, and the fish were each transferred to a $17-\mathrm{L}$ bucket $(\varnothing 36 \mathrm{~cm})$ filled with $4 \mathrm{~L}$ of an anesthetic solution (either AquaCalm at $0.08 \mathrm{~g} / \mathrm{L}, \mathrm{N}=21$; Benzocaine at $0.125 \mathrm{~g} / \mathrm{L}$, $\mathrm{N}=21$; or MS-222 at $0.15 \mathrm{~g} / \mathrm{L}, \mathrm{N}=22$; see Discussion for further information concerning doses). The behavior during the anesthetization process was recorded via a camcorder for further analysis. Fish were kept in the solution until they lost equilibrium and had no response to tactile stimuli [based on a preliminary study and corresponding to stage III plane 2 from Zahl et al. (2012)]. Immediately following this stage, the fish were photographed (see description below) and then measured and weighed. Blood was sampled via a heparinized syringe from the caudal vein, and then the fish were sacrificed. However, the AquaCalm group needed to be anesthetized with MS-222 $(0.15 \mathrm{~g} / \mathrm{L})$ before the blood sampling based on its more hypnotic rather than anesthetic effect (Ross and Ross, 2008). In addition, a noanesthetics group of fish were photographed first and then anesthetized (with MS-222 at 0.15 $\mathrm{g} / \mathrm{L}, \mathrm{N}=15$ ), measured, weighed, sampled and then sacrificed, and finally a control group were anesthetized (with MS-222 at $0.15 \mathrm{~g} / \mathrm{L}, \mathrm{N}=21$ ), measured, weighed, sampled and then sacrificed.

\section{Experiment 2: Long-term effect of anesthetics}

For the second experiment, a subset of the fish [body mass $\left(M_{\mathrm{B}}\right)$ of $108.3 \pm 19.3 \mathrm{~g}$ (mean \pm $\mathrm{SD}, \mathrm{N}=18)$ and a fork length $\left(L_{\mathrm{F}}\right)$ of $22.1 \pm 1.3 \mathrm{~cm}($ mean $\left.\pm \mathrm{SD}, \mathrm{N}=24)\right]$ from experiment 1 were transferred into a new tank $\left(1 \mathrm{~m}^{3}\right)$ supported with flow-through water for monitoring the long-term effect of the treatment. These fish were not sampled for blood nor sacrificed. Six fish from each of the anesthetics treatment, namely Aquacalm, Benzocaine, and MS-222, were marked by a small cut in the caudal fin (dorsal, ventral, or dorsal and ventral) directly after the anesthetic solution. In addition, six fish from the no-anesthetics group were transferred into the same tank (not marked, i.e. no cut in the dorsal fin) and in these fish only the length could be measured based on the fish not being anesthetized. The fish were kept for one week, during which they were fed. After one week, the fish were anesthetized using MS222 , measured, weighed and then sacrificed.

\section{Photographing procedure and following analysis}

Fish were photographed on both sides to evaluate a possible lateralization of spots using a Canon EOS 500D digital camera in a setup providing constant bright light (Figure 1). The fish were placed in a padded box with a clear Plexiglas ${ }^{\circledR}$ lid. The lid was used to keep the fish in position during the photographing. Photographs were analyzed as previously described (Backström et al., 2015). Briefly, carotenoid-based spots (Figure 1) were counted systematically in a rectangle $(2 \times 10 \mathrm{~cm})$ on each side using the free software ImageJ (Rasband, W.S., ImageJ, U. S. National Institutes of Health, Bethesda, Maryland, USA, http://imagej.nih.gov/ij/, 1997-2012.). 

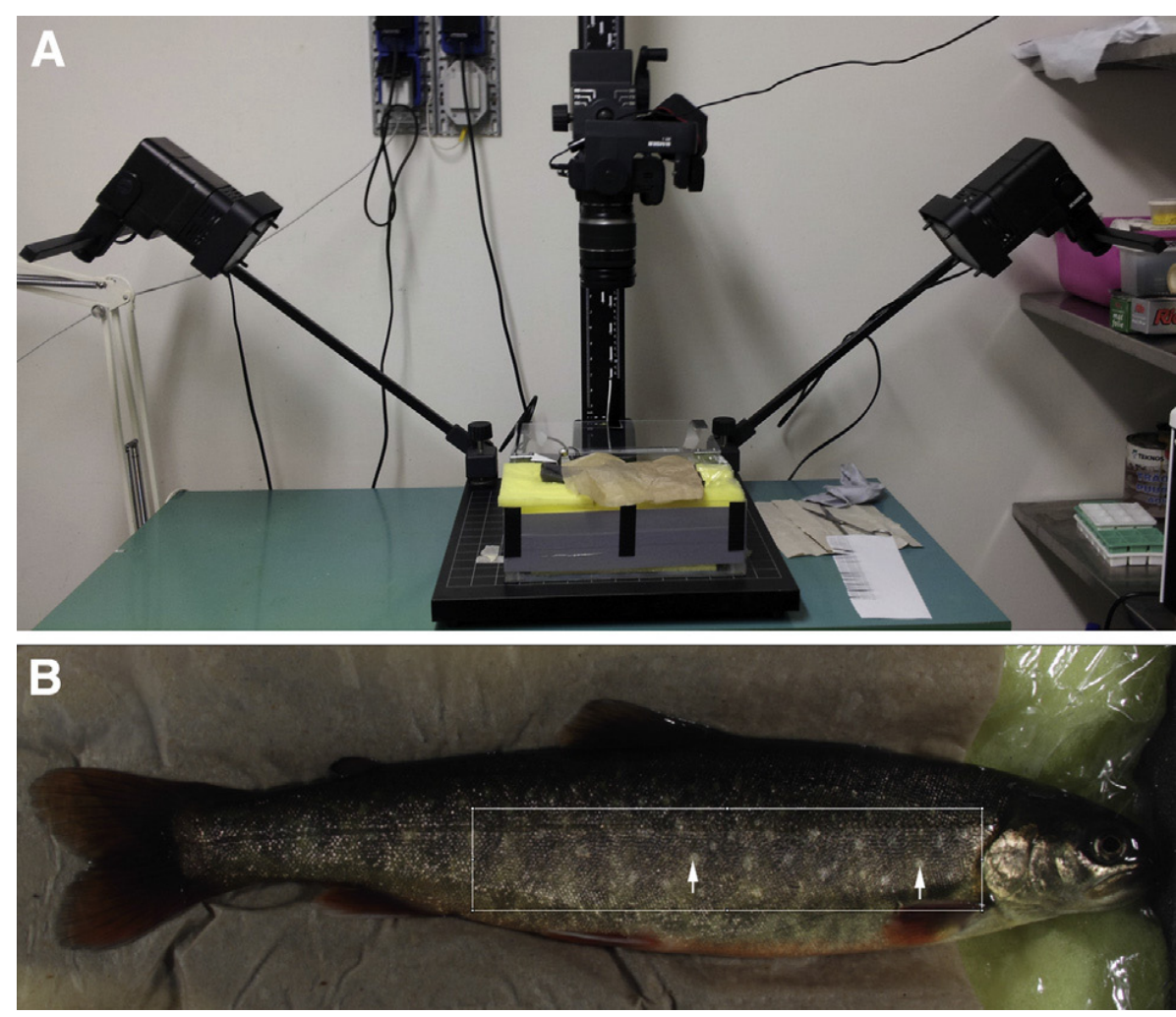

Figure 1. (A) The setup used for photographing individual fish. The setup included a holder for the camera to keep the same distance, lamps for providing constant light, and a box for keeping the fish still. The box also included a SpyderCUBE used for setting white balance during the pigmentation analysis. (B) Photograph depicting the selection box used for carotenoid-based pigmentation analysis. Arrows indicates typical spots that were counted.

\section{Sampling and analyses}

The blood was centrifuged and the plasma was collected and stored at $-20{ }^{\circ} \mathrm{C}$ until further analysis. Plasma was analyzed for cortisol using a commercial enzyme-linked immunosorbent assay (ELISA) kit (product \# 402710, Neogen corporation, Lexington, USA). Each sample was run in duplicates during a single assay with an intra-assay coefficient of variation of $2.09 \%$. In our analysis of the behavior during treatment with anesthetics the following was recorded: (1) activity until loss of equilibrium [anesthesia stage III plane 1, Zahl et al. (2012)], monitored by dividing the anesthetization bucket into quadrants via a cross and counting number of crossed lines per second until loss of equilibrium, (2) latency to loss of equilibrium and (3) latency to anesthesia [anesthesia stage III plane 2, Zahl et al. (2012)], defined as lost equilibrium and no response to three repeated tactile stimuli. The Fulton condition factor was calculated by the formula $K=100 \times M_{\mathrm{B}} \times L_{\mathrm{F}}{ }^{-3}$. Statistical analyses were done by Analysis of variance (ANOVA) followed by a LSD post hoc test. Correlations between behavior, physiology and pigmentation were processed by Pearson correlation test. All statistics were performed in IBM SPSS Statistics 20 (IBM Corporation, New York, USA) and data are presented as mean \pm SEM if not stated otherwise. The methodology of this study was approved by the Umeå Animal Research Ethical Committee. 
Table 1. The behavioural effects of anaesthetics during anaesthesia in juvenile Arctic charr. $\mathrm{N}=21$ for Aquacalm and Benzocaine, and 22 for MS-222.

\begin{tabular}{lcccc}
\hline Treatment & AquaCalm & Benzocaine & MS-222 & $P$-value \\
\hline $\begin{array}{l}\text { Activity (no/s) until loss of } \\
\text { equilibrium, stage III plane 1 }\end{array}$ & $0.15 \pm 0.03^{\mathrm{a}}$ & $0.32 \pm 0.03^{\mathrm{b}}$ & $0.18 \pm 0.03^{\mathrm{a}}$ & $<0.001$ \\
$\begin{array}{l}\text { Time (s) until loss of } \\
\text { equilibrium, stage III plane 1 }\end{array}$ & $35.9 \pm 2.06^{\mathrm{a}}$ & $43.1 \pm 2.8^{\mathrm{b}}$ & $35.4 \pm 1.2^{\mathrm{a}}$ & 0.006 \\
$\begin{array}{l}\text { Time (s) until anaesthesia, } \\
\text { stage III plane 2 }\end{array}$ & $91.6 \pm 6.3^{\mathrm{ab}}$ & $106.5 \pm 5.8^{\mathrm{b}}$ & $93.1 \pm 5.9^{\mathrm{a}}$ & 0.034 \\
& & & & \\
\end{tabular}

Values are mean $\pm \operatorname{SEM}(\mathrm{N})$ and different superscript letters shows differences between anaesthetic treatments (LSD post hoc, $P<0.05$ ).

\section{Results}

Experiment 1: Immediate effect of anesthetic treatment

During anesthetization there were several behavioral differences between the treatments (see Table 1). For instance, activity until loss of equilibrium [stage III plane 1 (Zahl et al., 2012)] was significantly different between anesthetic treatments (ANOVA: $F_{2,78}=11.609, P<0.001$ ).

Activity until loss of equilibrium was higher in Benzocaine-treated fish compared to both MS-222 (LSD post hoc: $P=0.037$ ) and AquaCalm-treated fish (LSD post hoc: $P=0.041$ ). Similarly, latency to loss of equilibrium differed between anesthetic treatments (ANOVA: $F_{2,78}=5.542, P=0.006$ ). Latency to loss of equilibrium was longer in Benzocaine-treated fish compared to both MS-222 (LSD post hoc: $P=0.002$ ) and AquaCalm-treated fish (LSD post hoc: $P=0.012$ ). Finally, latency to anesthesia [stage III plane 2 (Zahl et al., 2012)] (ANOVA: $F_{2,78}=3.522, P=0.034$ ) was longer in Benzocaine-treated fish compared to MS-222-treated fish (LSD post hoc: $P=0.011$ ) but no difference was noted between AquaCalm and Benzocaine (LSD post hoc: $P=0.071$ ) or MS-222 (LSD post hoc: $P=0.582$ ). Further, the different behaviors during anesthesia were associated with each other. Latency to loss of equilibrium was positively associated to latency to anesthesia (Pearson correlation: $P<0.001$ ) and activity until loss of equilibrium (Pearson correlation: $P=0.004$ ), pooling all treatments.

There were differences between treatments in stress response (ANOVA: $F_{4,69}=6.740$, $P<0.001$, see Figure 2). Plasma cortisol levels were higher in the no-anesthetics group than in AquaCalm (LSD post hoc: $P=0.002$ ), Benzocaine (LSD post hoc: $P=0.003$ ), MS-222 treated fish (LSD post hoc: $P=0.003$ ), and the control group (LSD post hoc: $P<0.001$ ). Further, the control group had lower cortisol levels than Benzocaine (LSD post hoc: $P=0.043$ ), and MS222-treated fish (LSD post hoc: $P=0.045$ ), but not AquaCalm (LSD post hoc: $P=0.074$ ). 


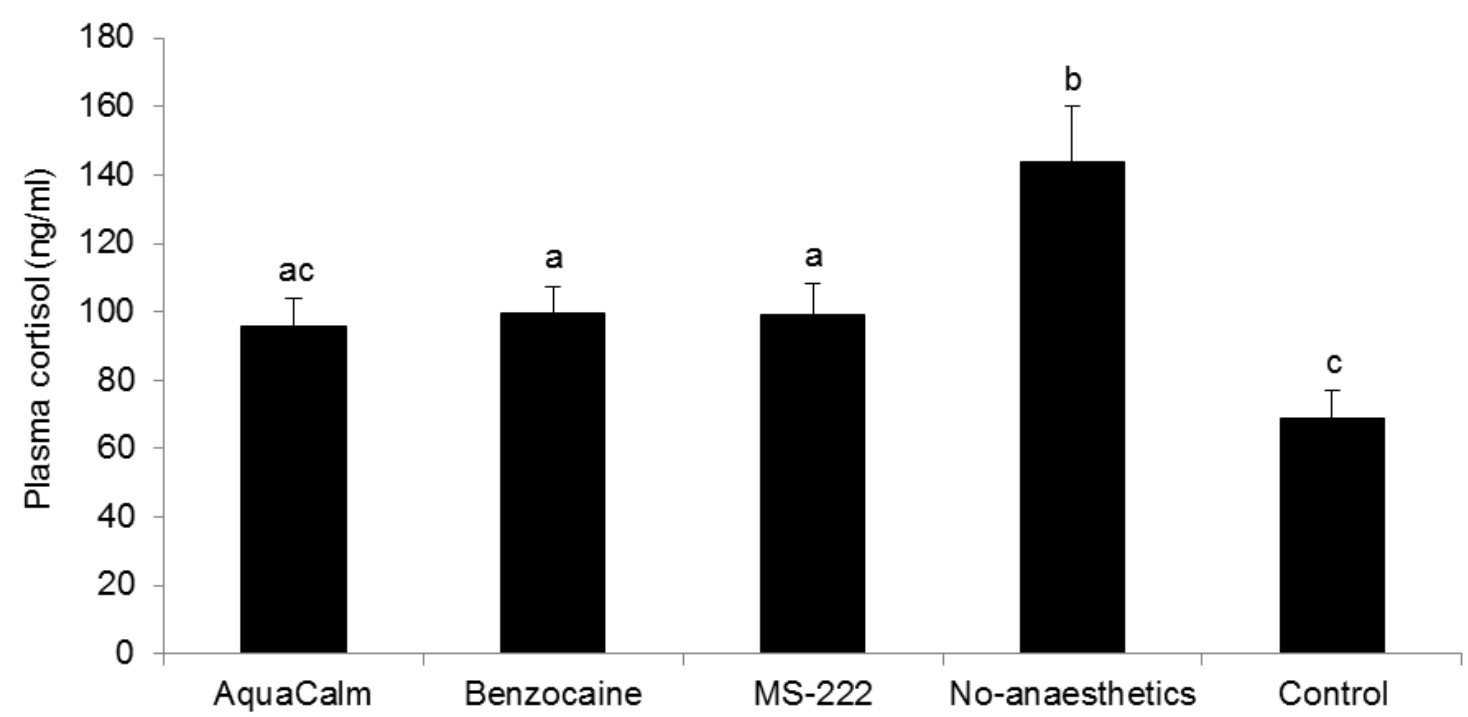

Figure 2. Plasma cortisol levels after treatments. Values are mean \pm S.E.M and different superscript letters indicates differences between treatments (LSD post hoc, $P<0.05$ ).

Concerning the carotenoid-based spots (see Figure 3) there were significant differences by treatment on both the right (ANOVA: $F_{3,84}=6.590, P<0.001$ ) and the left side (ANOVA: $F_{3,84}=3.801, P=0.013$ ). On the right side the no-anesthetics group had fewer spots compared to AquaCalm (LSD post hoc: $P=0.008$ ), Benzocaine (LSD post hoc: $P=0.010$ ), and MS-222treated fish (LSD post hoc: $P<0.001$ ), and on the left side the no-anesthetics group had fewer spots than AquaCalm (LSD post hoc: $P=0.028$ ) and MS-222-treated fish (LSD post hoc: $P=0.002$ ) but not Benzocaine (LSD post hoc: $P=0.184$ ). There were no differences in number of spots between the anesthetic treatments on the right or the left side.

Further, behavior was also connected with pigmentation. Activity until loss of equilibrium was negatively correlated to spots on the right side (Pearson correlation: $P=0.042$ ) but not the left side (Pearson correlation: $P=0.101$ ), and latency to loss of equilibrium was also negatively correlated to spots on the right (Pearson correlation: $P=0.021$ ) as well as left side (Pearson correlation: $P=0.019)$. Considering the different anesthetics separately also showed some differences in behavioral and physiological associations. For instance, in AquaCalmtreated fish latency to anesthesia was positively associated to plasma cortisol levels (Pearson correlation: $P=0.016)$. In Benzocaine-treated fish, latency to loss of equilibrium was negatively correlated to spots on the right (Pearson correlation: $P=0.002$ ) and left side (Pearson correlation: $P=0.001$ ), and latency to anesthesia was negatively associated to spots on the right side (Pearson correlation: $P=0.031$ ) but not the left side (Pearson correlation: $P=0.115)$. However, no connections between behavior, physiology, and pigmentation were apparent in MS-222-treatment. 


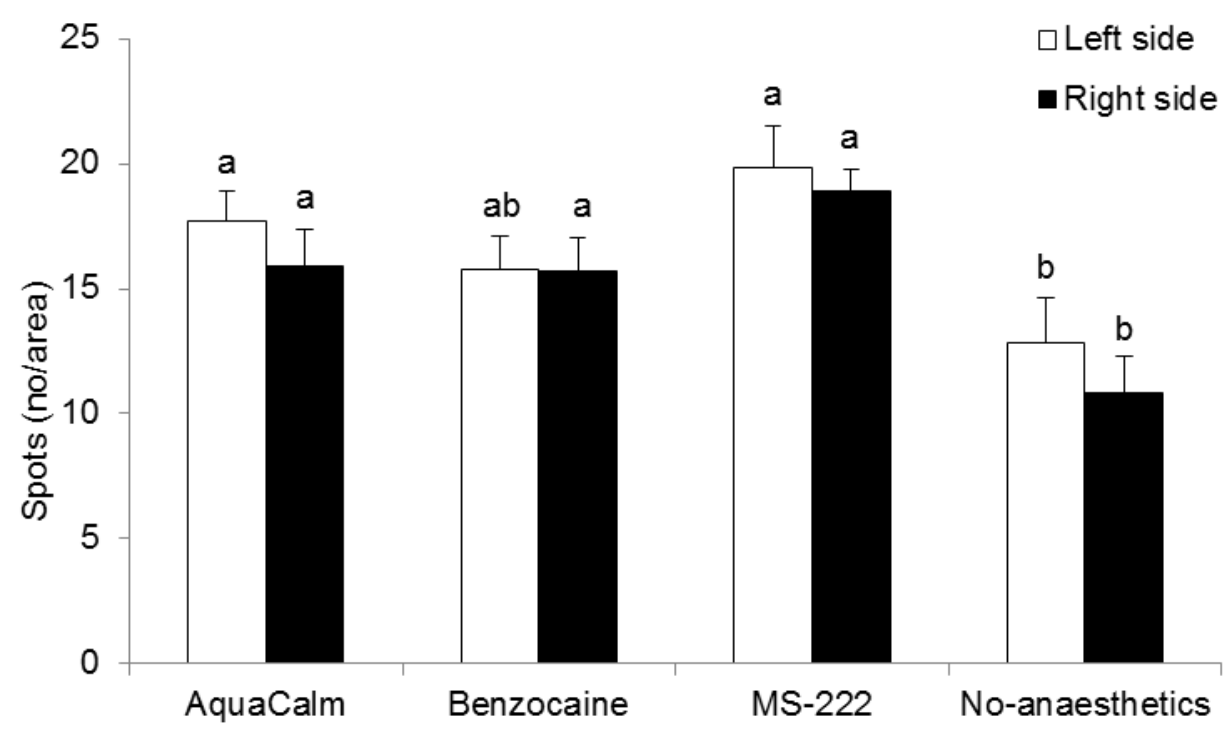

Figure 3. Carotenoid-based spots in juvenile Arctic charr. Values are means \pm S.E.M. Different superscript letters shows differences in number of spots on the same side between different treatments (LSD post hoc, $P<0.05$ ).

\section{Experiment 2: Long-term effect of anesthetics}

All Arctic charr were alive and appeared healthy one week after the photographing procedure. The Fulton condition factor did not differ between treatments neither before (ANOVA: $F_{2,17}=1.228, P=0.321$ ) nor after one week (ANOVA: $F_{3,23}=0.778, P=0.520$ ).

\section{Discussion}

One of the main purposes of our study was to investigate if the anesthetics could be used for simplifying the photographing procedure and thus make it less stressful for the fish. Plasma cortisol levels were higher in the no-anesthetics group compared to the anesthetic groups, indicating that the photographing process indeed is stressful. This is further corroborated by the result that controls, which were treated as the anesthetic groups but not being photographed, had significantly lower cortisol levels than photographed individuals except AquaCalm treated fish. It is possible that the sampling of blood prolonged the handling time in the no-anesthetics group as fish were handled more after they were first photographed, including dip netting, and then anesthetized using MS-222. This delay probably led to higher cortisol levels in the no-anesthetics group as time is an important factor in the stress response (Wendelaar Bonga, 1997). However, fish treated with AquaCalm were treated in a similar way to the controls, with an additional anesthetic in the form of MS-222 used after photographs but before blood sampling. With this treatment, plasma cortisol was at the same level as for the other anesthetics, supporting the view that being photographed without being anesthetized is more stressful.

No differences in plasma cortisol levels could be seen between the different anesthetic treatments in our study. A difference was expected between the effect of metomidate, the 
active compound in AquaCalm, which blocks the stress response release of cortisol (Neiffer and Stamper, 2009) compared to Benzocaine and MS-222 which could induce the stress response (Zahl et al., 2012). However, a recent study showed that metomidate induce a cortisol response, although to a lesser extent than other anesthetics, in several teleost fish including Atlantic salmon (Zahl et al., 2010). The additional anesthetic in the form of MS222 before blood sampling in experimental set-up for AquaCalm, may be a confounding factor, since it both added time until blood sampling and another anesthetic treatment. Further, MS-222 also stimulates cortisol release (Ross and Ross, 2008; Thomas and Robertson, 1991; Zahl et al., 2010). Therefore, the results in this study concerning plasma cortisol for AquaCalm are not conclusive.

Further, the anesthetic treatments gave apparent behavioral differences, with a slower induction of anesthesia by Benzocaine compared to MS-222 and AquaCalm. The hypnotic AquaCalm was probably delivered at a sedative rather than an anesthetic dose, which can explain the difference in behavior during anesthetization. The behavior immediately after anesthesia did not seem to differ between fish being subjected to either Benzocaine or MS222 (personal observation). Since the measures of activity during anesthetization were intercorrelated, there seems to be individual differences interacting with the effect of the anesthetic.

One caveat with this study is that only one dose of each of the anesthetics was used. However, the doses used are commonly used for anesthetizing teleost fish (Christiansen et al., 2013; Ghanawi et al., 2013; Neiffer and Stamper, 2009; Topic Popovic et al., 2012; Trushenski et al., 2012; Zahl et al., 2012), and the doses were based on a pre-study and strict criteria for anesthesia were used, that is, until the fish lost equilibrium and had no response to tactile stimuli. Further, the latency to anesthesia did not differ more than 20 seconds between treatments ( 87.7 to 106.5 seconds). Thus, the different effects of the anesthetics should be comparable.

The other main purpose of our study was to investigate if the anesthetics are affecting the carotenoid-based pigmentation. The results from this study show that anesthetization is indeed affecting the carotenoid-based pigmentation in Arctic charr but without apparent difference between compounds. The no-anesthetics group had fewer spots on both sides compared to fish exposed to anesthetics, with the exception of the left side in Benzocainetreated Arctic charr. Another caveat of this study is that pigmentation of undisturbed Arctic charr has not been analyzed. However, specialized tanks would be necessary for getting photographs of undisturbed charr and could also affect pigmentation as well as behavior. Since a difference between un-anesthetized and anesthetized charrs could be seen, one might conclude that the visual effect of the stress response, although maybe not the total, is possible to measure.

Individual variation in stress responsiveness or stress coping style could be important for animal welfare. In an earlier study, an apparent connection between the carotenoid spots and behavior has been reported for the Arctic charr (Backström et al., 2014). Carotenoid-based spots were also linked to stress coping style, with fish that had more spots showing higher plasma cortisol levels after a stressor (Backström et al., 2014). Behavior and carotenoidbased spots were associated, with effects seen on spots on both sides correlated to behavior. Fish with higher activity during anesthetization had less spots. It has been suggested that carotenoid-based spots are expressing a lateralization effect, i.e. that the left side is stronger connected to stress responsiveness (Backström et al., 2015). This is not apparent from these 
results, with the number of spots on both sides correlated to behavior. The link to the left side was still apparent in the association between spots and latency to loss of equilibrium during anesthetization, thus partly corroborating the earlier proposed link between stress responsiveness and the carotenoid spots on the left side.

Further, fish treated with anesthetics before being photographed had higher number of carotenoid-based spots than those in the no-anesthetics group, even though cortisol levels were lower. However, the plasma cortisol levels seen in the anesthetic treated fish were elevated compared to base levels generally found in unstressed fish (Wendelaar Bonga, 1997) including Arctic charr (Höglund et al., 2000; Höglund et al., 2002). Thus, it seems as if anesthesia would increase stress levels, even though cortisol levels were higher in the noanesthetics group fish. This is further corroborated by the elevated cortisol levels in the controls, treated as photographed fish except the actual photographing, compared to expected base levels in un-stressed Arctic charr (Höglund et al., 2000; Höglund et al., 2002). The apparent contradiction in the connection between spottiness and stress response, when comparing fish subjected to anesthetics before photographing and the no-anesthetics group, which were anesthetized after photographing, may reflect experienced differences in time elapse pre- and post-photographing as previously discussed. As the treated fish were first anesthetized, they experienced the anesthetics and a longer handling time before they were photographed, while the no-anesthetics group fish were photographed directly, but subsequently experienced a longer handling time before blood sampling. This implies that the cortisol levels in the no-anesthetics group could be an effect of the procedure and time following the photographing and thereby be disconnected from the spots. The change of spots in the treated fish may appear quickly (mean time for anesthesia $95.3 \mathrm{~s}$, after which photographs were taken). Our results evidently lead to the conclusion that methods must be carefully streamlined when investigating carotenoid-based pigmentation in Arctic charr.

Finally, the photographing procedure used did not harm the fish, since all fish survived and looked as before and did not change condition factors in the long-term experiment. Therefore all of the procedures used in this study can be considered as safe for common practice in Arctic charr.

In conclusion, these results seems to confirm that carotenoid-based pigmentation in Arctic charr is connected to stress coping style and therefore photographing could be used as a tool for selecting fish in experiments. However, the carotenoid-based pigmentation could be affected quickly by anesthetic treatments. Thus, careful planning of experiments, in which photos are used to analyze pigmentation, must include careful considerations of the potential effects of the treatment that will precede the photographing procedure.

\section{Acknowledgements}

This study was financed by the Swedish Research Council Formas. The idea for the experiments and their design was conceived by Tobias Backström and Martina Heynen. The data were analyzed and the paper written by Tobias Backström, Martina Heynen, Eva Brännäs, Jan Nilsson and Carin Magnhagen.

\section{Conflict of interest statement and author contributions}

No conflicts of interest to be declared. 


\section{References}

Backström, T., Brännäs, E., Nilsson, J., Magnhagen, C., 2014. Behaviour, physiology and carotenoid pigmentation in Arctic charr Salvelinus alpinus. J Fish Biol 84, 1-9.

Backström, T., Heynen, M., Brännäs, E., Nilsson, J., Magnhagen, C., 2015. Dominance and stress signalling of carotenoid pigmentation in Arctic charr (Salvelinus alpinus): Lateralization effects? Physiol. Behav. 138, 52e57.

Berglund, A., Bisazza, A., Pilastro, A., 1996. Armaments and ornaments: an evolutionary explanation of traits of dual utility. Biol J Linn Soc Lond 58, 385-399.

Christiansen, H.E., Gee, L.P., Mesa, M.G., 2013. Anesthesia of juvenile Pacific lampreys with MS222, BENZOAK, AQUI-S 20E, and Aquacalm. North American Journal of Fisheries Management 33, 269-276.

Conrad, J.L., Weinersmith, K.L., Brodin, T., Saltz, J.B., Sih, A., 2011. Behavioural syndromes in fishes: a review with implications for ecology and fisheries management. J Fish Biol 78, 395435.

Duarte, C.M., Marbá, N., Holmer, M., 2007. Rapid Domestication of Marine Species. Science 316, 382-383.

Ducrest, A.-L., Keller, L., Roulin, A., 2008. Pleiotropy in the melanocortin system, coloration and behavioural syndromes. Trends Ecol Evol 23, 502-510.

Erhard, H.W., Mendl, M., Ashley, D.D., 1997. Individual aggressiveness of pigs can be measured and used to reduce aggression after mixing. Appl Anim Behav Sci 54, 137-151.

Fredricks, K.T., Gingerich, W.H., Fater, D.C., 1993. Comparative cardiovascular effects of four fishery anesthetics in spinally transected rainbow trout, Oncorhynchus mykiss. Comp Biochem Physiol C Pharmacol Toxicol Endocrinol 104, 477-483.

Ghanawi, J., Monzer, S., Saoud, I.P., 2013. Anaesthetic efficacy of clove oil, benzocaine, 2phenoxyethanol and tricaine methanesulfonate in juvenile marbled spinefoot (Siganus rivulatus). Aquac. Res. 44, 359-366.

Gosling, S.D., 2001. From mice to men: What can we learn about personality from animal research? Psychol Bull 127, 45-86.

Hessing, M.J.C., Hagelsø, A.M., van Beek, J.A.M., Wiepkema, R.P., Schouten, W.G.P., Krukow, R., 1993. Individual behavioural characteristics in pigs. Appl Anim Behav Sci 37, 285-295.

Huntingford, F., Adams, C., 2005. Behavioural syndromes in farmed fish: implications for production and welfare. Behaviour 142, 1207-1221.

Huntingford, F.A., Adams, C., Braithwaite, V.A., Kadri, S., Pottinger, T.G., Sandøe, P., Turnbull, J.F., 2006. Current issues in fish welfare. J Fish Biol 68, 332-372.

Höglund, E., Balm, P., Winberg, S., 2000. Skin darkening, a potential social signal in subordinate arctic charr (Salvelinus alpinus): the regulatory role of brain monoamines and proopiomelanocortin-derived peptides. J Exp Biol 203, 1711-1721.

Höglund, E., Balm, P.H.M., Winberg, S., 2002. Behavioural and neuroendocrine effects of environmental background colour and social interaction in Arctic charr (Salvelinus alpinus). J Exp Biol 205, 2535-2543.

Kittilsen, S., Schjolden, J., Beitnes-Johansen, I., Shaw, J.C., Pottinger, T.G., Sørensen, C., Braastad, B.O., Bakken, M., Øverli, Ø., 2009. Melanin-based skin spots reflect stress responsiveness in salmonid fish. Horm Behav 56, 292-298.

Klemetsen, A., Amundsen, P.A., Dempson, J.B., Jonsson, B., Jonsson, N., O'Connell, M.F., Mortensen, E., 2003. Atlantic salmon Salmo salar L., brown trout Salmo trutta L. and Arctic charr Salvelinus alpinus (L.): a review of aspects of their life histories. Ecol Freshw Fish 12, 159.

Koolhaas, J.M., de Boer, S.F., Buwalda, B., van Reenen, K., 2007. Individual variation in coping with stress: A multidimensional approach of ultimate and proximate mechanisms. Brain Behav Evol 70, 218-226. 
Koolhaas, J.M., de Boer, S.F., Buwalda, B., van der Vegt, B.J., Carere, C., Groothuis, A.G.G., 2001. How and why coping systems vary among individuals, in: Broom, D.M. (Ed.), Coping with challenge: Welfare in animals including humans. Dahlem University Press, Berlin, pp. 197-209.

Koolhaas, J.M., Korte, S.M., De Boer, S.F., Van Der Vegt, B.J., Van Reenen, C.G., Hopster, H., De Jong, I.C., Ruis, M.A.W., Blokhuis, H.J., 1999. Coping styles in animals: current status in behavior and stress-physiology. Neurosci Biobehav R 23, 925-935.

Neiffer, D.L., Stamper, M.A., 2009. Fish sedation, anesthesia, analgesia, and euthanasia: considerations, methods, and types of drugs. ILAR J 50, 343-360.

Nilsson, J., Brännäs, E., Eriksson, L.O., 2010. The Swedish Arctic charr breeding programme. Hydrobiologia 650, 275-282.

Olsen, Y.A., Einarsdottir, I.E., Nilssen, K.J., 1995. Metomidate anaesthesia in Atlantic salmon, Salmo salar, prevents plasma cortisol increase during stress. Aquaculture 134, 155-168.

Pickering, A.D., Pottinger, T.G., Christie, P., 1982. Recovery of the brown trout, Salmo trutta L., from acute handling stress: a time-course study. J Fish Biol 20, 229-244.

Ross, L.G., Ross, B., 2008. Anaesthetic and sedative techniques for aquatic animals. Blackwell Science.

Schjolden, J., Winberg, S., 2007. Genetically determined variation in stress responsiveness in rainbow trout: Behavior and neurobiology. Brain Behav Evolut 70, 227-238.

Shahidi, F., Synowiecki, J., Penney, R.W., 1994. Chemical nature of xanthophylls in flesh and skin of cultured Arctic char (Salvelinus alpinus L.). Food Chem 51, 1-4.

Sloan Wilson, D., Clark, A.B., Coleman, K., Dearstyne, T., 1994. Shyness and boldness in humans and other animals. Trends Ecol Evol 9, 442-446.

Small, B.C., 2003. Anesthetic efficacy of metomidate and comparison of plasma cortisol responses to tricaine methanesulfonate, quinaldine and clove oil anesthetized channel catfish Ictalurus punctatus. Aquaculture 218, 177-185.

Svensson, P.A., Wong, B.B.M., 2011. Carotenoid-based signals in behavioural ecology: a review. Behaviour 148, 131-189.

Thomas, P., Robertson, L., 1991. Plasma cortisol and glucose stress responses of red drum (Sciaenops ocellatus) to handling and shallow water stressors and anesthesia with MS-222, quinaldine sulfate and metomidate. Aquaculture 96, 69-86.

Topic Popovic, N., Strunjak-Perovic, I., Coz-Rakovac, R., Barisic, J., Jadan, M., Persin Berakovic, A., Sauerborn Klobucar, R., 2012. Tricaine methane-sulfonate (MS-222) application in fish anaesthesia. J. Appl. Ichthyol. 28, 553-564.

Trushenski, J.T., Bowzer, J.C., Bowker, J.D., Schwarz, M.H., 2012. Chemical and electrical approaches to sedation of cobia: Induction, recovery, and physiological responses to sedation. Mar Coast Fish 4, 639-650.

Wendelaar Bonga, S.E., 1997. The stress response in fish. Physiol Rev 77, 591-625.

Zahl, I., Kiessling, A., Samuelsen, O., Olsen, R., 2010. Anesthesia induces stress in Atlantic salmon (Salmo salar), Atlantic cod (Gadus morhua) and Atlantic halibut (Hippoglossus hippoglossus). Fish Physiol Biochem 36, 719-730.

Zahl, I., Samuelsen, O., Kiessling, A., 2012. Anaesthesia of farmed fish: implications for welfare. Fish Physiol Biochem 38, 201-218.

Øverli, Ø., Winberg, S., Pottinger, T.G., 2005. Behavioral and neuroendocrine correlates of selection for stress responsiveness in rainbow trout - a review. Integr Comp Biol 45, 463-474. 